\title{
Numerical simulation of an instrument to determine the thermal conductivity of conductive solids
}

\author{
J. Xamán ${ }^{1, a}$, J. Esquivel-Ramon ${ }^{2}$, Y. Chávez $^{1}$ And I. Hernández-PÉrez ${ }^{1}$ \\ 1 Centro Nacional de Investigación y Desarrollo Tecnológico, CENIDET-TecNM-SEP, Prol. Av. Palmira S/N. Col. Palmira, \\ Cuernavaca 62490 Morelos, México \\ 2 Instituto Tecnológico de Campeche, ITCampeche - TecNM-SEP, Carretera Campeche-Escárcega km 9, Lerma 24500 \\ Campeche, México
}

Received 1 August 2015, Accepted 14 March 2016

\begin{abstract}
In this paper the design of a cut bar system to determine the thermal conductivity of conductive solid materials is presented. The system works under the comparative method, therefore two reference samples with known thermal conductivity are needed. The thermal design consisted on defining the physical configuration of the thermal system, materials to use and their dimensions, in order to evaluate their thermal performance by varying these parameters to calculate the maximum percentage design error. Given that the thermal design was parametric, the finite volume method was used to solve the heat conduction equation in the cut bar system, which allowed us to vary the different parameters that make up the thermal system such as length and diameter of the bars, insulation thickness, type of reference material, etc. The numerical code developed was verified with one analytical solution. It was found that, the thermal design of a cut bar instrument to determine the thermal conductivity of solid materials within the interval $0.58 \leqslant \lambda \leqslant 429 \mathrm{~W} \cdot \mathrm{m}^{-1} \cdot \mathrm{K}^{-1}$ shows a maximum design error of $3.77 \%$ associated to the length of the sample material. The results in this paper allow one to kwon the error by design which can be taken into account as a source of uncertainty when determining the thermal conductivity of solid materials.
\end{abstract}

Key words: Numerical simulation / thermal conductivity

\section{Introduction}

The thermophysical properties are divided into two different categories: thermodynamic and transport properties. Thermodynamic properties such as density $(\rho)$ and specific heat $\left(C_{p}\right)$ are related to the equilibrium of a system. On the other hand, transport properties include coefficients such as dynamic viscosity $\mu$ (for momentum transfer) and thermal conductivity $\lambda$ (for heat transfer). In particular, the thermal conductivity of a solid can be four times higher in magnitude than the conductivity of fluids (Fig. 1) [1]. Over the last decades, several methods to measure the thermal conductivity of different solid materials have been developed. The making and use of new materials, and the importance of their application aiming to more accurate results, have improved the already known methods and the development of new techniques to determine thermal conductivity.

Theoretically, the general method to determine the thermal conductivity of a solid must set up a gradient

${ }^{a}$ Corresponding author: jxaman@cenidet.edu.mx temperature through the sample or specimen and determine the resulting local heat flux. Nevertheless, this is not possible because the local heat flux cannot be measured directly. The heat flux can be constant or can change over time. Depending on the nature of the heat flux, the methods of measurement can be classified into techniques in steady state and techniques in transient state. In steady state techniques, the thermal conductivity is determined after reaching the thermal equilibrium. In order to set up a controlled heat flux, the sample is placed between a heating unit (heat source) and a cooling unit (heat sink). The heat source as well as the heat sink are arranged so that the heat can flow in the longitudinal or radial direction of the sample. Therefore, many steady state techniques can be divided into longitudinal heat flux techniques and radial heat flux techniques. In the steady state methods, the temperature profile through the sample is constant over time. Then, thermal conductivity with a unidirectional heat flux is computed directly by the Fourier's Law as:

$$
\lambda=\frac{q}{A} \frac{\Delta x}{\Delta T}
$$




\section{Nomenclature}

\begin{tabular}{|ll|}
\hline$A$ & Area, $\mathrm{m}^{2}$ \\
$a$ & Bar length, $\mathrm{m}$ \\
$d$ & Bar radius, $\mathrm{m}$ \\
$E$ & Maximum percentage design error, $\%$ \\
$e$ & Insulation material radius, $\mathrm{m}$ \\
$C_{p}$ & Specific heat, $\mathrm{J} \cdot \mathrm{kg}^{-1} \cdot \mathrm{K}{ }^{-1}$ \\
$h$ & Convective heat transfer coefficient, $\mathrm{W} \cdot \mathrm{m}^{-2} \cdot \mathrm{K}^{-1} \cdot$ \\
$q$ & Heat flux, W. ${ }^{-2}$ \\
$q_{M}$ & Heat flux in the sample material, $\mathrm{W} \cdot \mathrm{m}^{-2}$ \\
$q_{R 1}$ & Heat flux in the reference material $1, \mathrm{~W} \cdot \mathrm{m}^{-2}$ \\
$q_{R 2}$ & Heat flux in the reference material $2, \mathrm{~W} \cdot \mathrm{m}^{-2}$ \\
$r_{A}$ & Radius for the insulation material, $\mathrm{m}$ \\
$r_{M}$ & Radius of the sample material, $\mathrm{m}$ \\
$r_{R}$ & Radius of the reference material, $\mathrm{m}$ \\
$T$ & Temperature, ${ }^{\circ} \mathrm{C}$ or $\mathrm{K}$ \\
$T E$ & Evaluation temperature, ${ }^{\circ} \mathrm{C}$ or $\mathrm{K}$ \\
$T_{c}$ & Hot temperature, ${ }^{\circ} \mathrm{C}$ or $\mathrm{K}$ \\
$T_{f}$ & Cold temperature, ${ }^{\circ} \mathrm{C}$ or $\mathrm{K}$ \\
$T_{\infty}$ & Ambient temperature, ${ }^{\circ} \mathrm{C}$ or $\mathrm{K}$ \\
$t$ & Time, $\mathrm{s}$ \\
$z_{M}$ & Length of the sample material, $\mathrm{m}$ \\
$z_{R}$ & Length of the reference material, $\mathrm{m}$ \\
\hline
\end{tabular}

\begin{tabular}{|ll|}
\hline$\alpha$ & Thermal diffusivity, $\mathrm{m}^{2} \cdot \mathrm{s}^{-1}$ \\
$\Delta T$ & Temperature difference $\left(T_{c}-T_{f}\right),{ }^{\circ} \mathrm{C}$ or $\mathrm{K}$ \\
$\lambda$ & Thermal conductivity, W.m ${ }^{-1} \cdot \mathrm{K}$ \\
$\lambda_{A}$ & Thermal conductivity of the insulation material, $\mathrm{W} \cdot \mathrm{m}^{-1} \cdot \mathrm{K}$ \\
$\lambda_{M}$ & Thermal conductivity of the sample material, $\mathrm{W} \cdot \mathrm{m}^{-1} \cdot \mathrm{K}^{-1}$ \\
$\lambda_{R 1}$ & Thermal conductivity of the reference material $1, \mathrm{~W} \cdot \mathrm{m}^{-1} \cdot \mathrm{K}-1$ \\
$\lambda_{R 2}$ & Thermal conductivity of the reference material $2, \mathrm{~W} \cdot \mathrm{m}^{-1} \cdot \mathrm{K}^{-1}$ \\
$\rho$ & Density, kg.m ${ }^{-3}$ \\
\hline
\end{tabular}

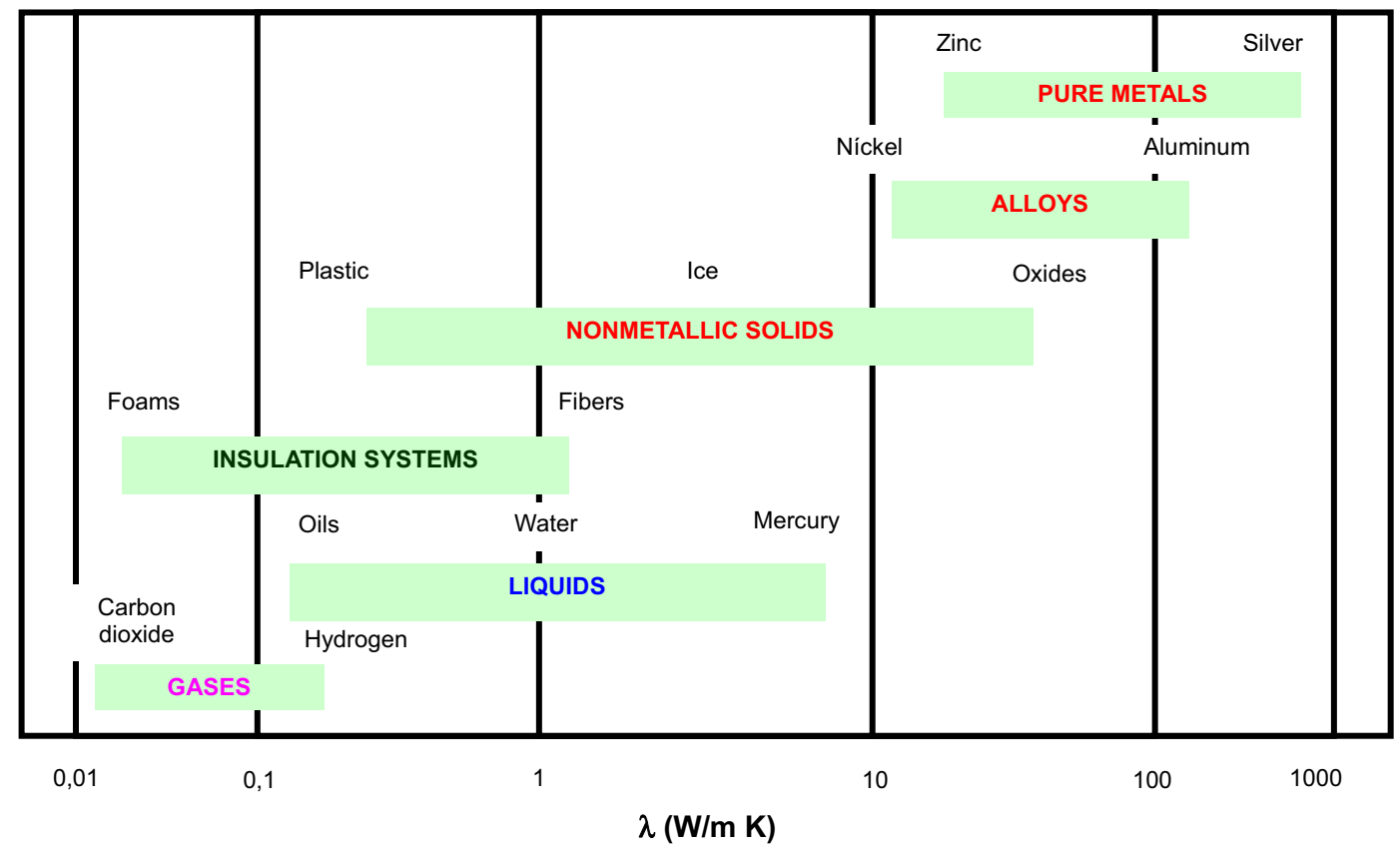

Fig. 1. Thermal conductivity scale for several states of matter at normal temperatures and pressure [1]. 
According to the previous equation, the heat flux $(q)$ is applied normal to the cross area $(A)$ of the sample so that it can have isothermal surfaces. The amount of heat flux applied over the sample is controlled in order to achieve thermal stability and set a temperature difference $\left(\Delta T=T_{2}-T_{1}\right)$ through the sample thickness $\left(\Delta x=x_{2}-x_{1}\right)$. The difficulties involved using Equation (1) to determine thermal conductivity $(\lambda)$ are mainly related to maintaining adequate boundary conditions. These boundary conditions must be adiabatic for two reasons: (a) Equation (1) considers unidirectional and uniform heat flux, this condition can be achieved if and only if there are no heat losses through the broadside of the sample; otherwise, temperature distribution over the sample surface get distorted; and (b) the heat flux cannot be measure directly, it is computed from the electric power applied to the heat source $(P=V I, V=$ electric tension and $I=$ electric current). Therefore, the sample as well as the heat source unit broadside have to be insulated from the environment to prevent any loss of heat. The way to maintain adiabatic conditions over the sample is by means of a guard with a heating element or an adequate thermal insulating material. In practice, all these precautions have to be taken into account and can be effectives up to a point (quasi adiabatic condition), so many corrections have to be applied. Corrections for certain type of errors can be controlled because they systematically alter the experimental conditions. The test to determine the thermal conductivity in steady state takes many work hours; after setting up the source and heat sink units, sometimes the system takes up to $10 \mathrm{~h}$ to reach the thermal equilibrium. The design of this type of system can be very sophisticated; nevertheless, the physical principle that supports the steady state techniques is based on a simple mathematical model. In addition, few measurements such as tension, electric current, sample thickness and temperature are required, for this reason these methods are called absolute techniques.

On the other hand, in transient techniques the temperature distribution within the sample varies over space and time. The equation used for this technique is given by:

$$
\frac{\partial\left(\rho C_{p} T\right)}{\partial t}=\frac{\partial}{\partial x}\left(\lambda \frac{\partial T}{\partial x}\right)
$$

Some methods determine thermal diffusivity $(\alpha=\lambda / \rho$ $C_{p}$ ); after that, thermal conductivity can be indirectly obtained by knowing the density $(\rho)$ and specific heat $\left(C_{p}\right)$ of the sample. Some solutions for the parabolic Equation (2) allow having a variety of equations, with variations not only in geometry but in the way the heat flux is imposed also. Some transient techniques are also called dynamic techniques. Here, thermal conductivity is computed from the temperature increment that results when a constant heat flux is applied and has been measured. These techniques, as well as the steady state techniques require adiabatic conditions. The way to achieve adiabatic conditions in a dynamic technique is by using embedded electric heaters; in this manner, the adiabatic condition can be easily reached due to the short time required to make a measurement. The heaters, which are surrounded by the sample, are mathematically treated as semi-infinite or infinite to avoid heat losses or leakage on the broadside or in radial direction. The most important advantage when using dynamic techniques is the short period of time required to make a measurement. As a consequence, heat losses have poor influence on measurements. The disadvantage on these methods is that they usually require complex mathematical models and some of them with difficult boundary conditions to achieve experimentally.

In general, among the methods reported to determine thermal conductivity, we can find the following:

(a) Heat flow meter method: ASTM C518 [2].

(b) Hot wire method: ASTM C1113 [3].

(c) Hot guarded plate method: ASTM C177 [4].

(d) Heat flow method (small test samples): ASTM F433 [5].

(e) Comparative-longitudinal heat flow method: ASTM E1225 [6].

(f) Flash method: ASTM E1461 [7].

Most of the methods reported are adequate to analyze materials with thermal conductivity lower than $80 \mathrm{~W} \cdot \mathrm{m}^{-1} \cdot \mathrm{K}^{-1}$ and only two of them can be applied to higher values, these methods are: the comparative method and the laser pulse method, the last one highlights over the comparative method for many reasons, some of these advantages are: measurement speed, wide range in conductivities, wide range on measurement temperature and the small size of the samples. Nevertheless, the main disadvantages are: higher uncertainties compared to the comparative method, is inadequate to apply on materials with large microstructures and/or porous, besides it requires data acquisition equipment and high speed sensors. The comparative method on the other hand, is convenient because it improves the uncertainty when determining the thermal conductivity regarding other methods. However, there are many parameters that have not been already properly set down when designing a thermal system to determine this physical property. Table 1 shows a summary of the characteristics and considerations taken into account by several authors on the analysis and application of the cut bar instrument (comparative method), from which the following conclusion is presented:

(1) The largest conductivity value measured by any constructed equipment was $200 \mathrm{~W} \cdot \mathrm{m}^{-1} \cdot \mathrm{K}^{-1}$, with an uncertainty lower than $10 \%$.

(2) Most of the authors use two reference materials.

(3) The lowest uncertainty in measurements was achieved on the evaluation temperature interval of 293 to $593 \mathrm{~K}$.

(4) On three of the cases contact resistance is treated by applying force, death weight or clamping screws. Nevertheless, the cases where contact resistance was not taken into account the uncertainty value was lower.

(5) The heat flow through the samples was computed using the Fourier's Law, except in one case where the 
J. Xamán et al.: Mechanics \& Industry 18, 105 (2017)

Table 1. Characteristics and considerations taken into account by different authors.

\begin{tabular}{|c|c|c|c|c|c|c|c|c|c|}
\hline Author & $\begin{array}{c}\lambda \\
\left(\mathrm{W} \cdot \mathrm{m}^{-1} \cdot \mathrm{K}^{-1}\right)\end{array}$ & $T(\mathrm{~K})$ & $\begin{array}{c}\text { Uncertainty } \\
y(\%)\end{array}$ & $\begin{array}{l}\text { Number of } \\
\text { reference } \\
\text { materials }\end{array}$ & $\begin{array}{l}\text { Type } \\
\text { of } \\
\text { study }\end{array}$ & $\begin{array}{l}\text { Constact } \\
\text { resistance } \\
\text { treatment }\end{array}$ & $\begin{array}{c}\text { Computation } \\
\text { of the Heat } \\
\text { flow }\end{array}$ & $\begin{array}{l}\text { Cross } \\
\text { section } \\
\text { shape }\end{array}$ & $\begin{array}{l}\text { Use } \\
\text { of } \\
\text { guard }\end{array}$ \\
\hline$[6]$ & 0.2 to 200 & 90 to 1300 & 6.8 & 2 & Theoretical & $\begin{array}{c}\text { Force or death } \\
\text { weight death weight }\end{array}$ & $\begin{array}{c}\text { Fourier's } \\
\text { Law }\end{array}$ & circular & yes \\
\hline$[8]$ & 0.15 to 150 & 100 to 1300 & 6.8 & 1 or more & $\begin{array}{c}\text { Theoretical } \\
\text {-Experimental }\end{array}$ & Force & $\begin{array}{c}\text { Fourier's } \\
\text { Law } \\
\end{array}$ & circular & yes \\
\hline$[9]$ & 0.2 to 200 & 100 to 1300 & 10 & 2 & Experimental & Hydraulic force & $\begin{array}{l}\text { Fourier's } \\
\text { Law }\end{array}$ & circular & yes \\
\hline$[10]$ & 0.2 to 150 & 115 & 7 & 2 & Theoretical & Clamping screws & $\begin{array}{l}\text { Fourier's } \\
\text { Law }\end{array}$ & circular & yes \\
\hline$[11]$ & 0.046 to 386 & 293 to 593 & 5 & 2 & $\begin{array}{c}\text { Theoretical } \\
\text {-Experimental }\end{array}$ & $\begin{array}{c}\text { Not } \\
\text { considered }\end{array}$ & Joule effect & circular & no \\
\hline$[12]$ & 0.58 to 100 & 323 & 6 & 1 & Theoretical & $\begin{array}{c}\text { Not } \\
\text { considered }\end{array}$ & $\begin{array}{c}\text { Fourier's } \\
\text { Law }\end{array}$ & squared & no \\
\hline$[13]$ & 398 & 200 to 1200 & 10 & 1 & $\begin{array}{c}\text { Theoretical } \\
\text {-Experimental }\end{array}$ & $\begin{array}{c}\text { Not } \\
\text { considered }\end{array}$ & $\begin{array}{l}\text { Fourier's } \\
\text { Law Law }\end{array}$ & circular & no \\
\hline
\end{tabular}

heat flow was computed by the Joule effect, this one showed the lowest uncertainty value.

(6) The guard was included in only three cases.

(7) Most of the cross section samples were rounded and only in one case the sample was square and it showed low uncertainty value.

Xing et al. $[14,15]$ and Jensen at al. $[16,17]$ simulated the comparative method to obtained the thermal conductivity of the TRISO fuel compact, the authors shown the uncertainty analysis by using a guarded cut-bar technique.

Recently, Reif-Acherman [18] presents a historicalexperimental methods for determining thermal conductivities of metals. He presented the whole evolution, highlighting the main advantages and disadvantages of those most important, some of the technological circumstances that prompted the emergence of new techniques, as well as their comparative estimation capabilities. Also, Xing et al. $[19,20]$ used the guarded cut-bar technique for an experimental study toinvestigate the resulting error under different guarding conditions using stainless steel 304. The result of this study provides a general guideline for the specific measurement method and for methods requiring optimal guarding or insulation.

The equation for the comparative method of cut bar system to determine " $\lambda$ " considers that the heat flux is only axial, in practice this does not happen due to the radial heat losses, but it is possible to minimize radial heal flow with an adequate measurement system design. From here, many questions arise: What type of material should be used for the bars guard? What should be the dimensions and characteristics of the reference material? Which materials can be measured using this technique? What should be the dimensions of the materials under study?, etc. We would have the answers to these questions if the behavior of the temperature field inside the composite system was known, this would allow us to determine the heat flux in order to decide when the radial heat flux is minimum. To cope with this problem, the profile temperatures should be determined experimentally or theoretically. The experimental option is discarded because there are numerous parameters to evaluate, which would have a cost in time and money. A theoretical analytical or numerical formulation would allow carrying out the parametric study in a very short time and a low economical cost compared to the experimental solution.

Therefore, the goal of this research work is to determine the thermal design parameters that define a measurement instrument to measure thermal conductivity of conductive solids, which works under the principle of a secondary method (comparative method).

\section{Physical model}

The comparative method to evaluate thermal conductivity consists on setting down a constant heat flux through two reference samples with known thermal conductivity and length, between which the specimen of unknown thermal conductivity is placed. A temperature gradient is set up between both extremes of the composite bar until it reaches the thermal equilibrium with one end at hot temperature $T_{c}$ provided by the heat source, and the opposite end at cold temperature $T_{f}$ using a heat sink. The amount of heat passing through each sample can be calculated by measuring the temperature at specific points as shown in Figure 2 and applying the Fourier's Law, that is:

$$
\begin{gathered}
q_{R 1}=\lambda_{R 1} \frac{T_{2}-T_{1}}{Z_{2}-Z_{1}} \\
q_{M}=\lambda_{M} \frac{T_{4}-T_{3}}{Z_{4}-Z_{3}}
\end{gathered}
$$




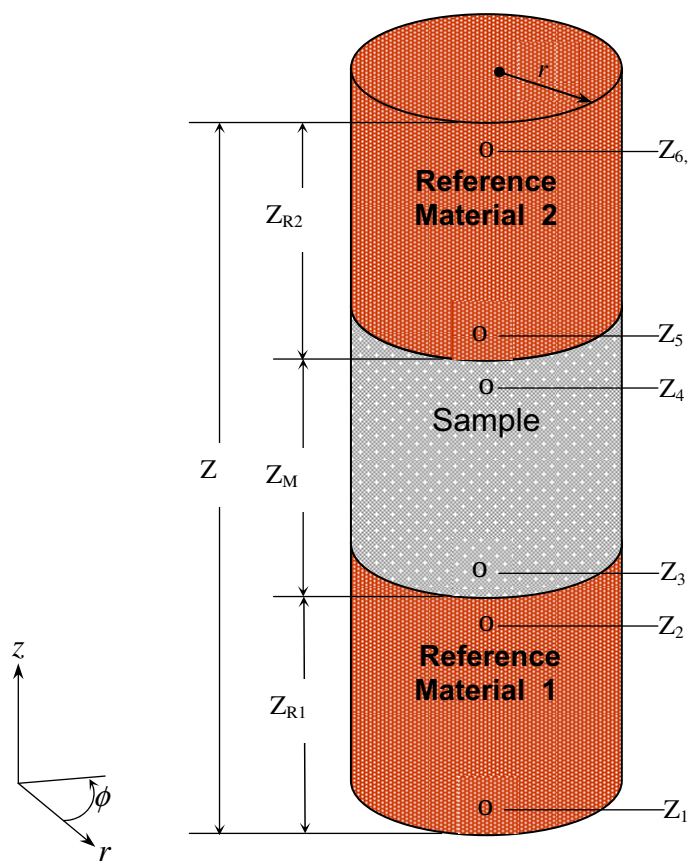

Fig. 2. Scheme of the comparative-longitudinal heat flow system (cut-bar system) showing the locations of temperature sensors.

$$
q_{R 2}=\lambda_{R 2} \frac{T_{6}-T_{5}}{Z_{6}-Z_{5}}
$$

The heat flux through each of the materials of the composite bar is constant, but in order to decrease the uncertainty in measurements, the heat flux passing through the cross section sample is computed as the arithmetic average of the reference materials $\left(q_{R 1}\right.$ and $\left.q_{R 2}\right)$, this is $q_{M}=\frac{q_{R 1}+q_{R 2}}{2}$ and substitution of equations (3a) $-(3 \mathrm{c})$, makes possible to obtain the equation to determine the thermal conductivity as:

$$
\lambda_{M}=\frac{Z_{4}-Z_{3}}{T_{4}-T_{3}}\left[\frac{\lambda_{R 1}}{2}\left(\frac{T_{2}-T_{1}}{Z_{2}-Z_{1}}\right)+\frac{\lambda_{R 2}}{2}\left(\frac{T_{6}-T_{5}}{Z_{6}-Z_{5}}\right)\right]
$$

The previous equation is called the work equation, because once the distances and temperatures at the specific points along the composite bar have been measured, the thermal conductivity can be determined. Some considerations have to be made when designing an experimental system that works under the previous work equation to determine the thermal conductivity of a sample:

(a) Perfect contact between materials, it means, contact resistance is negligible.

(b) The thermal conductivity of the reference material as well as the insulation (guard) is known.

(c) All materials are isotropic and homogeneous.

(d) The materials thermal conductivity is constant all along the temperature interval

(e) Temperatures at the heat source $T_{c}$ and the heat sink $T_{f}$ of the system are constant and uniform.

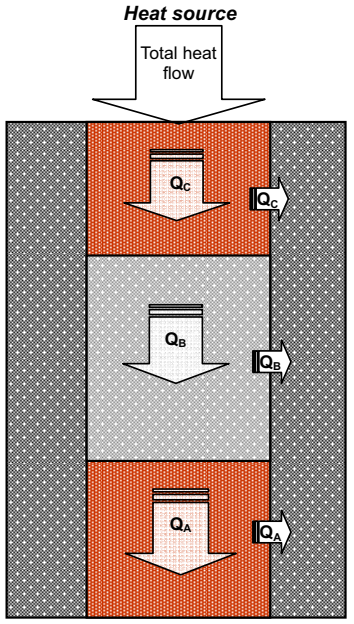

Heat sink

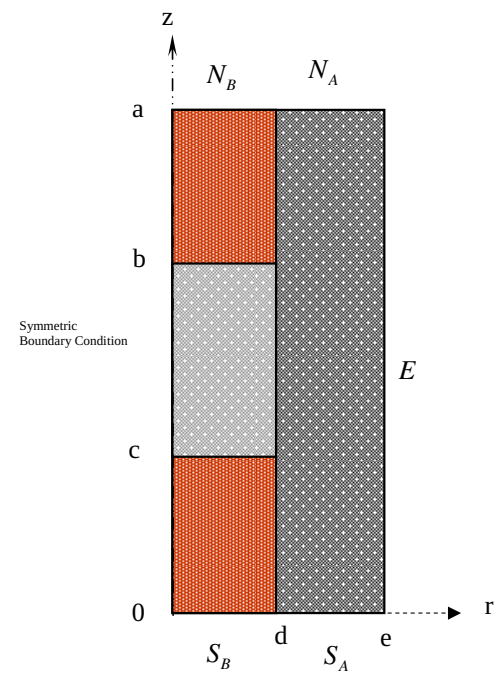

Fig. 3. Physical model of the cut bar system. (f) The cross section area of the reference material and the sample are the same.

(g) There is no heat generation on any of the materials.

The physical configuration of the cut bars apparatus consists on a composite system of materials with different thermal properties. Figure 3 shows the longitudinal section of the system, where the sample to be evaluated is placed between two other materials of known thermal properties and all the three elements are surrounded at the exterior by an insulating material. The heat passing through the system flows in longitudinal and radial direction. In longitudinal direction, the heat passing through the reference materials at the ends is computed using the Fourier's Law, by measuring temperatures and lengths on each of them. Therefore, taking into account the energy conservation principle we have: $Q_{A}=Q_{B}=Q_{C}$ with this relationship it is possible to determine the thermal conductivity of the sample material using Equation (4) previously deducted under the same energy conservation principle and the Fourier equation. Due to the geometry of the composite system, it is expected the temperature distribution to be the same at any longitudinal cut of the system such that the temperature field is only function of the radius $r$ and length $z$.

\section{Mathematical model}

Heat propagation produces a temperature distribution on the media as a result of the conditions prevailing at the boundaries of the system. The way in which the heat spreads is governed by the "Heat diffusion equation". This equation is derived from an energy balance on a differential element in cylindrical coordinates, and it indicates the heat going through on axial, angular and radial direction, as shown in Figure 4. If in the energy balance, the medium is considered isotropic and homogeneous, the result is the transient heat diffusion general equation in cylindrical coordinates. In our case, the analysis will be carried out in 


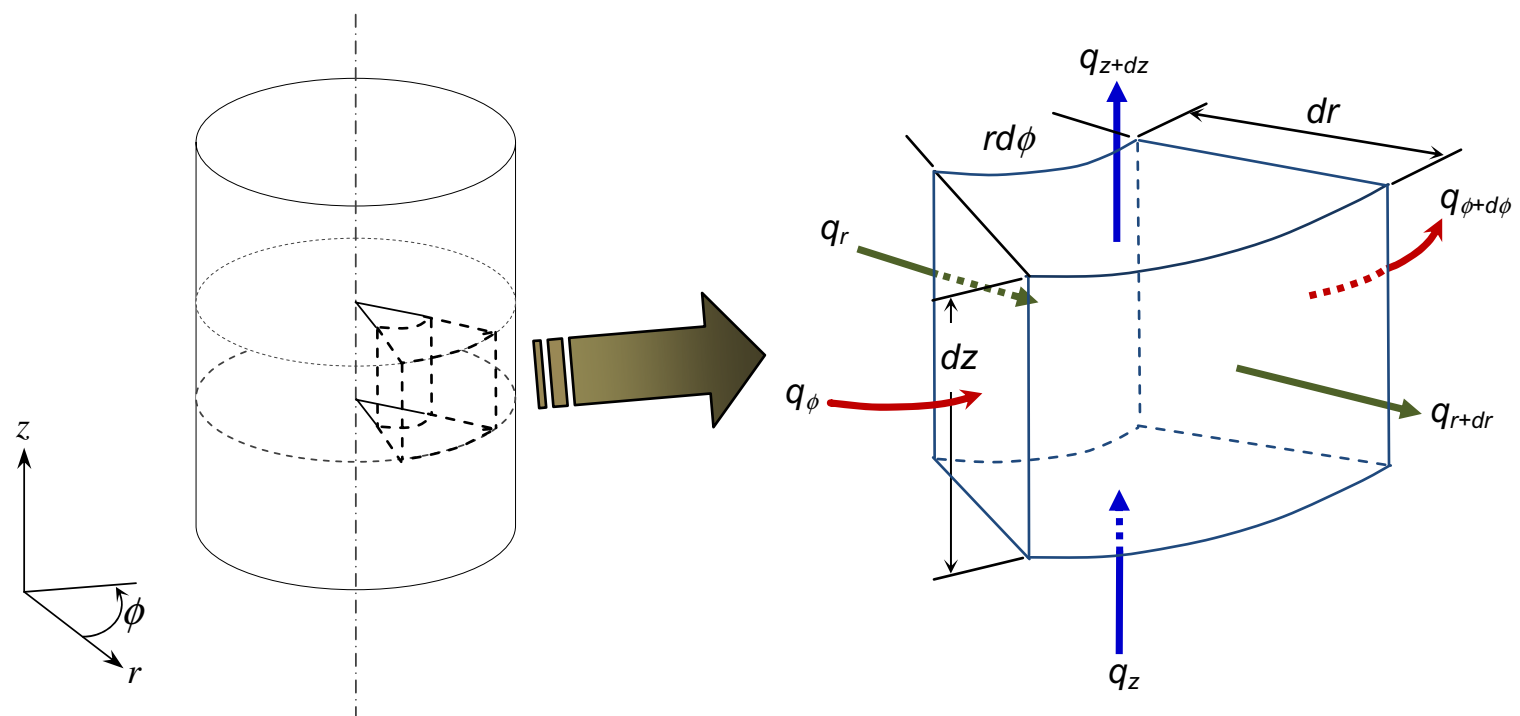

Fig. 4. Differential element on the cylindrical coordinate system.

steady state and it is expected the temperature distribution on the system to be function of the radius $r$ and length $z$ only, besides there is no heat generation inside the system. Taking into account the previous considerations, the mathematical model for the study of the heat transfer in the cut bar instrument is:

$$
\frac{1}{r} \frac{\partial}{\partial r}\left(\lambda \cdot r \frac{\partial T}{\partial r}\right)+\frac{\partial}{\partial z}\left(\lambda \frac{\partial T}{\partial z}\right)=0
$$

Taking into account the symmetry of the system under analysis, the boundary conditions are defined as:

$$
T=T_{f} \text { for } z=0,0 \leqslant r \leqslant d
$$

$$
\begin{gathered}
\lambda \frac{\partial T}{\partial z}=h\left(T-T_{\infty}\right) \quad \text { for } z=0, d<r \leqslant e \\
T=T_{c} \text { for } z=a, 0 \leqslant r \leqslant d \\
\lambda \frac{\partial T}{\partial z}=h\left(T-T_{\infty}\right) \text { for } z=a, d<r \leqslant e \\
\frac{\partial T}{\partial r}=0 \text { for } r=0,0<z<a \\
\lambda \frac{\partial T}{\partial r}=h\left(T-T_{\infty}\right) \text { for } r=e, 0<z<a
\end{gathered}
$$

The properties for each material that conform the cut bars system are:

$$
\begin{aligned}
& \lambda=\lambda_{R 1} \text { for } 0 \leqslant r \leqslant d, 0 \leqslant z \prec c \\
& \lambda=\lambda_{M} \text { for }, 0 \leqslant r \leqslant d, c \leqslant z \prec b \\
& \lambda=\lambda_{R 2} \text { for } 0 \leqslant r \leqslant d, b \leqslant z \leqslant a \\
& \lambda=\lambda_{A} \text { for } \quad d<r \leqslant e, 0 \leqslant z \leqslant a
\end{aligned}
$$

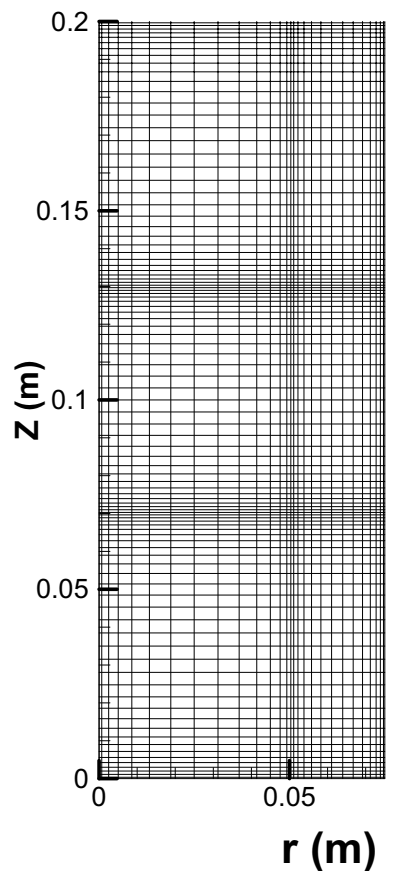

Fig. 5. Differential element on the cylindrical coordinate system.

\section{Numerical procedure}

\subsection{Discretization}

The governing equation is discretized using the finite volume method [21] over a non uniform mesh (Fig. 5). The governing equation is integrated over a control volume and each term on the integration balance is approximated in terms of the discrete values of $\phi$ on the nodal points:

$$
a_{P} \phi_{P}^{n+1}=\sum_{n b=E, O, N, S} a_{n b} \phi_{n b}^{n+1}+b^{n}
$$




$$
\begin{aligned}
\theta_{R} & =\sum_{m=1}^{\infty} \times \frac{\left.d J_{1}\left(\beta_{m} d\right)\left\{\lambda_{s} \theta_{c} \sinh \left[\beta_{m}(a-b)\right]+\lambda_{p}\right) \cosh \left(\beta_{m} b\right) \cdot \theta_{f}\right\}}{\beta_{m}\left\{\lambda_{s} \sinh \left[\beta_{m}(a-b)\right] \cosh \left(\beta_{m} b\right)+\lambda_{p} \sinh \left(\beta_{m} b\right) \cosh \left[\beta_{m}(a-b)\right]\right\}} \\
\theta_{c} & =\frac{T_{c}-T_{\mathrm{amb}}}{\Delta T} \quad y \quad \theta_{f}=\frac{T_{f}-T_{\mathrm{amb}}}{\Delta T}
\end{aligned}
$$

where $n$ and $n b$ indicate the number of iteration and the coefficient of the neighbor nodes, respectively. $b$ represents the source terms and $\phi$ is the discrete value of the dependent variable over the control volume. The diffusive terms are approximated by a central scheme. For the system to be analyzed, composed by different homogeneous materials, it is necessary to evaluate the physic properties, for this evaluation we used a harmonic interpolation reported by [21]. The system of algebraic equations resulting from Equation (7) is solved using the line by line method (LBL) alternating directions (ADI). Under relaxation is introduced by the false transient. Global convergence is reached when the residual values of Equation (7) are small enough $\left(10^{-10}\right)$. This convergence criterion is applied to assure an acceptable converged solution.

A study of grid independency was carried out for the cut bar system with grids going from $21 \times 61$ to $71 \times$ 211 , with increments of 10 computational nodes in radial direction and 30 in axial direction. For this exercise four typical modeling cases were considered. Based on the local design error $\left(E=\frac{\left|q_{R}\right|-\left|q_{z}\right|}{\left|q_{R}\right|} \times 100\right.$, where: $q_{R}=$ heat flow resultant vector and $q_{z}=$ heat flow axial component), the maximum obtained percentage deviation was $13 \%$ for a mesh of $41 \times 121$ and $51 \times 151$, so a grid of $41 \times 121$ was selected for the study.

\subsection{Verification of the developed numerical code}

To assure the correct development of the computational code, verification was carried out comparing the results with the analytical solution of a problem that corresponds to a solid bar conformed by two materials with first class boundary conditions. This exercise is carried out in order to obtain more reliable numerical results. The bars system is composed by two materials of different thermal properties, for verification these materials were: Plumb at the upper side and Silver at the lower side, with thermal conductivity of $\lambda_{P}=35.3$ and $\lambda_{S}=429.0 \mathrm{~W} \cdot \mathrm{m}^{-1} \cdot \mathrm{K}^{-1}$ respectively. The bars system has constant temperature values at the ends: hot temperature $T_{c}=40{ }^{\circ} \mathrm{C}$ at $z=a$, cold temperature $T_{f}=20{ }^{\circ} \mathrm{C}$ at $z=0$, radius of $r=d$ and ambient temperature $T_{\mathrm{amb}}=30^{\circ} \mathrm{C}$, as shown in Figure $6 \mathrm{a}$. The analytical solution of this problem was derived using the separation of variables method, and to simplify the problem a change of variable with $\theta=\frac{T-T_{\mathrm{amb}}}{\Delta T}$ was made, where $\Delta T=T_{c}-T_{f}$, the analytical solution was obtained in terms of the Bessel functions of the first kind as [22]:

$$
\begin{aligned}
& \theta(r, \mathrm{z})=\sum_{m=1}^{\infty} \frac{J_{0}\left(\beta_{m} r\right)}{N\left(\beta_{m}\right) \sinh \left(\beta_{m} b\right)} \\
& \times\left[\frac{d}{\beta_{m}} \theta_{f} J_{1}\left(\beta_{m} d\right) \sinh \left[\beta_{m}(b-z)\right]+\sinh \left(\beta_{m} z\right) \theta_{R}\right] \\
& \theta(r, z)=\sum_{m=1}^{\infty} \frac{J_{0}\left(\beta_{m} r\right)}{N\left(\beta_{m}\right) \sinh \left[\beta_{m}(a-b)\right]} \\
& {\left[\frac{d}{\beta_{m}} \theta_{c} J_{1}\left(\beta_{m} d\right) \sinh \left[\beta_{m}(z-b)\right]+\sinh \left[\beta_{m}(a-z)\right] \theta_{R}\right]} \\
& \quad \times \text { for } b<z<a
\end{aligned}
$$

where

$$
\text { see equation above }
$$

The norm equation is $N\left(\beta_{m}\right)=\frac{d^{2}}{2} J_{1}^{2}\left(\beta_{m} d\right)$ and the corresponding equation for its eigenvalues values is $J_{0}\left(\beta_{m} d\right)=$ 0 [23].

Figure $6 \mathrm{~b}$ shows the isothermals obtained analytically and numerically, it can be seen that the numerical results foretell qualitatively the analytical profiles; the maximum percentage difference obtained is $0.21 \%$. Based on these results it can be concluded that the developed numerical code is reliable.

\section{Results}

The thermal design of a measurement system mainly requires several parameters to be previously defined; nevertheless, it is necessary to know the contribution of each parameter to the system as a function of their characteristics, properties and dimensions. Numerical modeling is a tool that provides an economical advantage and time saving to this purpose, because it allows us to analyze the thermal behavior of the system taking into account the influence of each parameters involved.

Before analyzing the effect of each parameter it is important to understand the heat transfer phenomenon in the cut bar system. Therefore, the parameters of study will be shown first, later the conduction phenomenon will be described for a typical (representative) case with and without insulation and at the end the analysis of the parameters involved will be shown. 


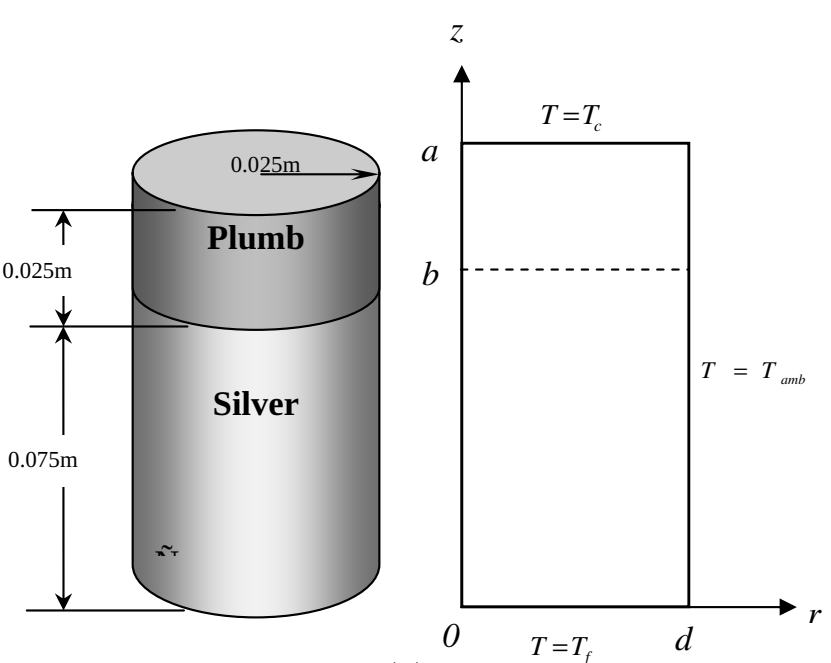

(a)

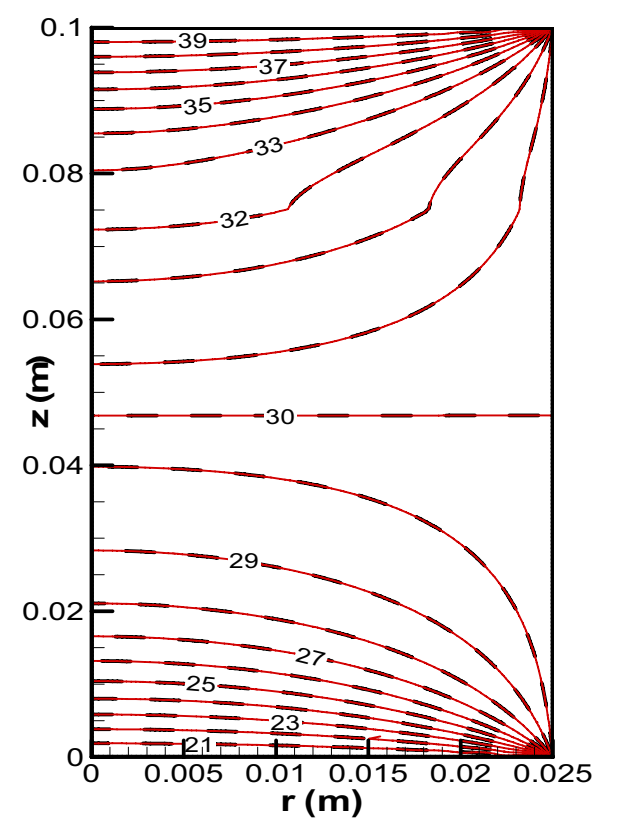

(b)

Fig. 6. (a) Physical model of the composite bars conformed by two materials and (b) Isothermals for the composite bar $\left({ }^{\circ} \mathrm{C}\right)$ obtained analytically and numerically.

\subsection{Parameters of study}

The scope of this research work involves two types of parameters: fixed and variables. The fixed parameters are those that remain constant for every case of study. The variable parameters on the contrary, change and produce a new case of study for each different value of the parameter under study. Table 2 shows the variable and fixed parameters for this study, and their corresponding values.

The fixed parameters were set based on the following: among the different insulation materials commercially available the extruded polystyrene $\left(0.035 \mathrm{~W} \cdot \mathrm{m}^{-1} \cdot \mathrm{K}^{-1}\right)$ was chosen because it is easily manipulable for
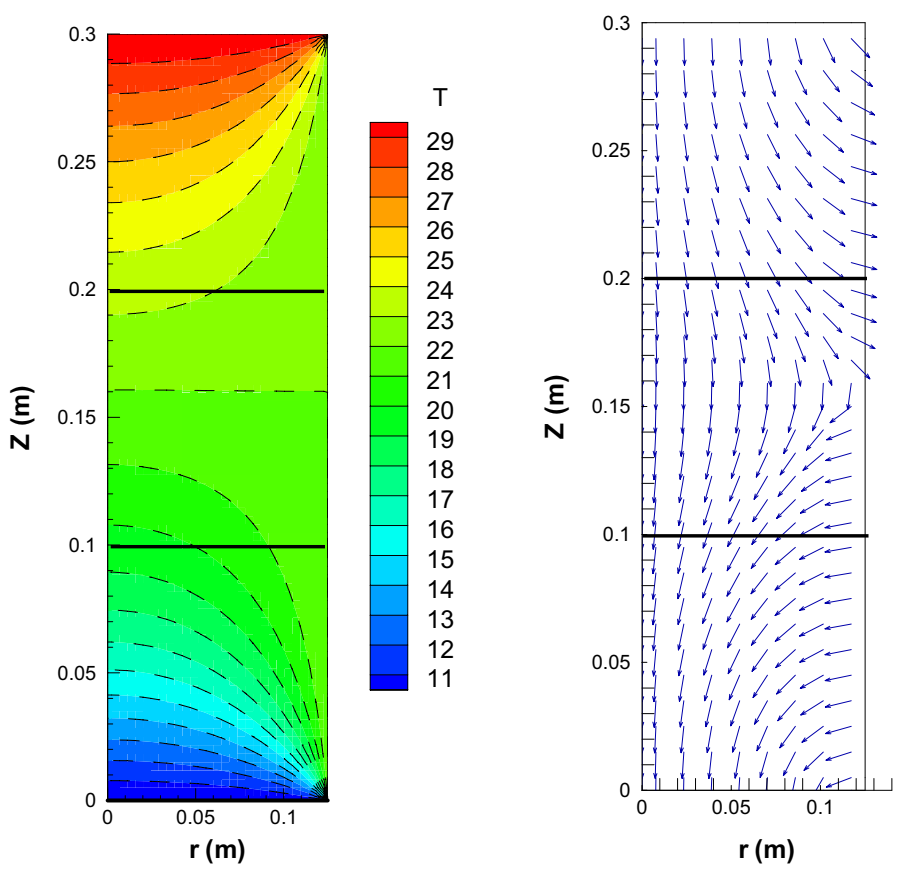

Fig. 7. Temperature profiles and heat flow inside a solid composite bar.

experimentation. The radius of the sample and reference material were chosen based on the availability of the materials in that size. The thicknesses of the insulation material are $12.5,37.5,62.5$ and $87.5 \mathrm{~mm}$ defined as the difference between the insulation material radius $\left(r_{\mathbf{A}}\right)$ and the reference material $\left(r_{\mathbf{R}}\right)$ radius, equivalent to $1 / 2,11 / 2$, $21 / 2$ and $31 / 2$ inches respectively. The length of the reference material was set such that it was larger than the diameter in order to propitiate axial unidirectional conduction heat transfer. The type of the sample and reference material for this study were selected to embrace a wide interval of values for the thermal conductivity; these values are shown in Table 3.

\subsection{Heat transfer in the cut bar system}

Heat transfer inside a solid material occurs when a temperature gradient between two points in the medium is present; Figure 7 shows the temperature profile and the heat flow vector in a bar composed by copper as the reference material and aluminum as the sample material. High temperature is at the top of the bar and low temperature is at the bottom, surrounded by ambient temperature with values of 30,10 and $22{ }^{\circ} \mathrm{C}$ respectively. The length of the sample material is the same as the reference material $(0.1 \mathrm{~m})$. Insulation guard is not present. This figure can be clearly seen than the temperature profiles are not gradually stratified. Also it can be observed that radial heat flow is present, this flow has to be minimized in order to obtain a linear temperature profile inside the bar to reduce the design error. The temperature profiles as well as the heat flow graphs obtained for different materials, lengths and gradient temperatures are similar to 
J. Xamán et al.: Mechanics \& Industry 18, 105 (2017)

Table 2. Parameters for the numerical study.

\begin{tabular}{cc}
\hline \multicolumn{2}{c}{ VARIABLE PARAMETERS } \\
\hline Parameter & Value \\
\hline Radius for the insulation material $\left(r_{A}\right)$ & $25,50,75 \mathrm{y} 100 \mathrm{~mm}$ \\
Length of the sample material $\left(z_{M}\right)$ & $25,50,75 \mathrm{y} 100 \mathrm{~mm}$ \\
Evaluation temperature $(T E)$ & $25,50,75,100,150 \mathrm{y} 200{ }^{\circ} \mathrm{C}$ \\
Reference material & $($ see Table 3$)$ \\
Sample material & (see Table 3$)$ \\
\hline FIXED PARAMETERS \\
\hline Parameter \\
\hline Insulation material (extruded polystyrene) \\
Radius of the reference material $\left(r_{R}\right)$ & $0.035 \mathrm{~W} . \mathrm{m}^{-1} \cdot \mathrm{K}^{-1}$ \\
Radius of the sample material $\left(r_{M}\right)$ & $12.5 \mathrm{~mm}$ \\
Length of the reference material $\left(z_{R}\right)$ & $12.5 \mathrm{~mm}$ \\
\hline
\end{tabular}

Table 3. Thermal conductivity values for the sample and reference material.

\begin{tabular}{cc}
\hline Sample material & Thermal conductivity $\left(\mathrm{W} \cdot \mathrm{m}^{\mathbf{- 1}} \cdot \mathrm{K}^{\mathbf{- 1}}\right)$ \\
\hline Asbestos & 0.58 \\
Bakelite & 1.4 \\
Stainless steel & 14.2 \\
Plumb & 35.3 \\
Bronze & 52.0 \\
Tin & 66.6 \\
Iridium & 147.0 \\
Aluminum & 237.0 \\
Gold & 317.0 \\
Copper & 401.0 \\
Silver & 429.0 \\
\hline Reference material & \\
\hline Stainless steel & 14.2 \\
Bronze & 52.0 \\
Aluminum & 237.0 \\
Copper & 401.0 \\
\hline
\end{tabular}

that shown in Figure 7 when the insulation guard is not present.

Placing a low thermal conductivity material around the composite bar will allow minimizing the radial heat flow, in other words, most of the heat flow will go through the axial direction reducing with it the design error. Figure $8 \mathrm{a}$ shows the temperature profile and the heat flow vector inside the composite bar with Bakelite as the sample material and copper as the reference material, this bar is surrounded by an insulating material. It can be seen that most of the heat flows in axial direction; nevertheless, for the material under study (Bakelite), high gradient temperatures occur at the interface between the bar and the insulation due to the difference on the thermal properties of the bars material. For the same case, when the sample material Bakelite is changed by aluminum these high gradients are not present any more, and the temper- ature profiles inside the bar are practically linear all along the radius of the bar. The gradient at the composite bar causes axial heat flow all along and minimum radial heat flow (Fig. 8b).

Figure 9 shows the temperature distribution as a function of the axial dimension (height of the bar) for the specific radius defined on Figure 8 (configuration a) Copper-Bakelite-Copper and (b) Copper-AluminumCopper, both configurations with insulation material), the temperatures profile correspond to the temperature at the centre of the composite bar $(r=0.0 \mathrm{~mm})$ and at the interface between the bar and the guard $(r=12.08 \mathrm{~mm})$. In general, for both configurations it can be observed that the difference between the value of temperature at $r=0$ and $r=12.08 \mathrm{~mm}$ is negligible, minimizing the radial heat flow. For the case of the Bakelite as the sample material, it can be observed that most of the highest gradients 

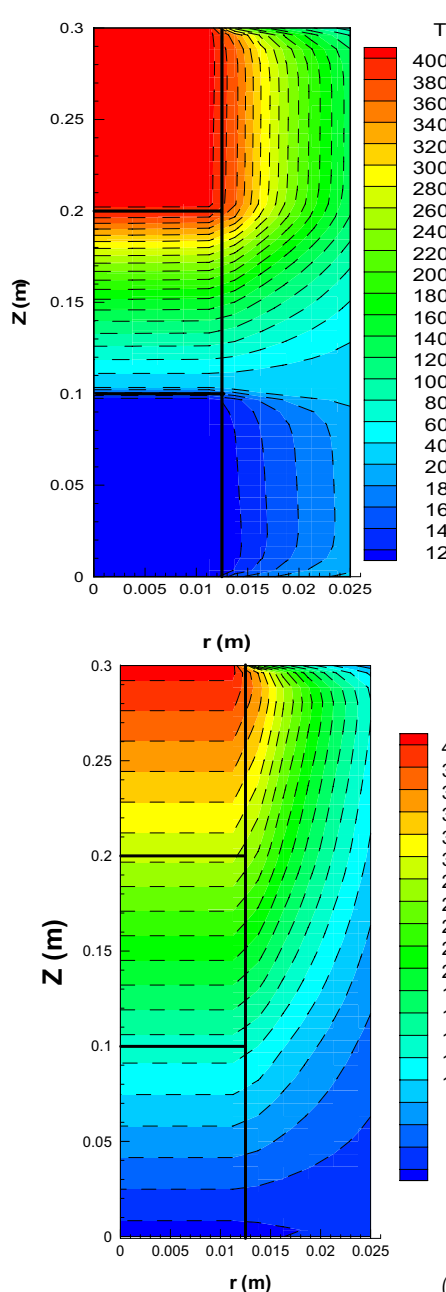

(a)
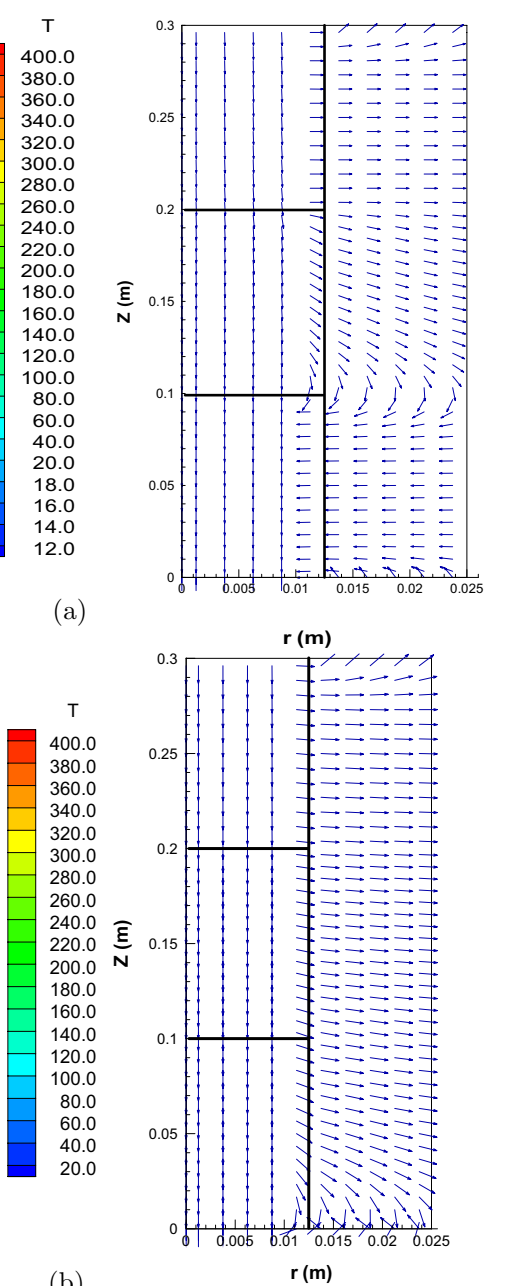

Fig. 8. Temperatures profile and heat flow inside a CopperBakelite-Copper (a) and Copper-Aluminum-Copper (b) composite bar with insulation material around the exterior radio.

are concentrated on the sample material; this is due to the low thermal conductivity of the sample regarding the reference material (highly conductive); on the contrary when the sample material is Aluminum, the axial gradients are practically linear all along the composite bar, it means that the slope remains almost constant, which is desirable on the design of a cut bars instrument to have an axial stratified temperature profile along the length of the bar. From this result it can be concluded that the thermal conductivity value of the sample material should not be much different from the reference; so, to determine experimentally the thermal conductivity of a specific material, the reference material has to be ad hoc, in order to avoid inadequate temperature gradients.

\subsection{Effect of the insulation material thickness $\left(r_{\mathrm{A}}\right)$}

The role of the insulation material is to minimize radial heat losses so to find out the optimal thickness is fundamental, since the lower the radial losses the lower

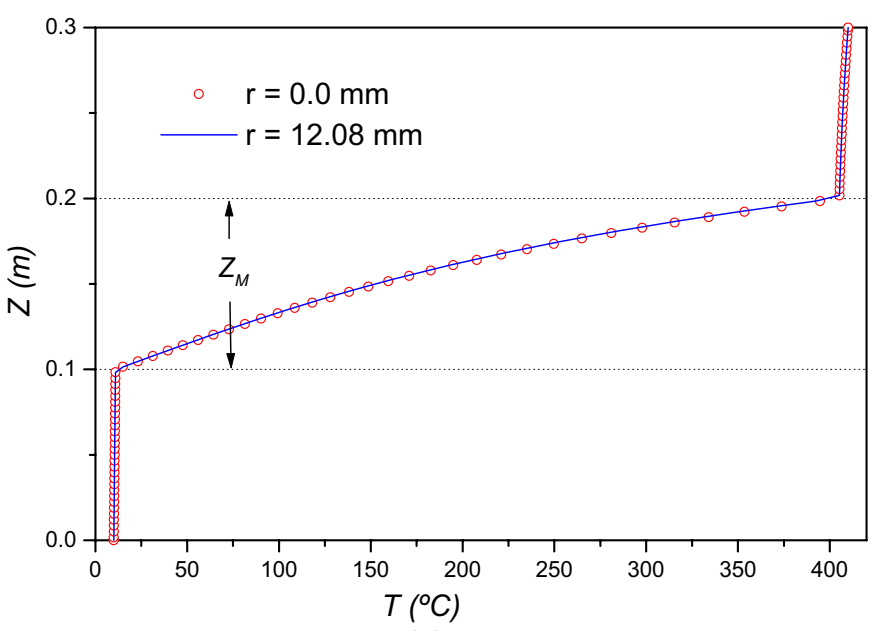

(a)

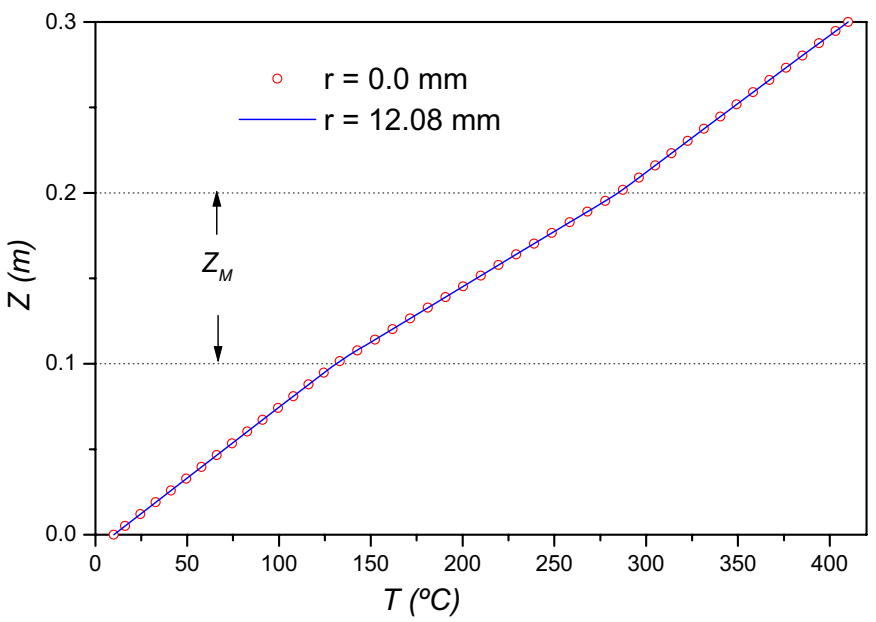

(b)

Fig. 9. Temperatures distribution at the centre of the bar $(r=0.0 \mathrm{~mm})$ and at the interface $(r=12.08 \mathrm{~mm})$ between the bar and the guard for a: (a) Bakelite sample and (b) Aluminum sample.

the contributions to the error design as a source of uncertainty.

Figure 10 shows the effect of the insulation material thickness for different sample materials and two reference materials: (a) Stainless steel and (b) Copper. To analyze the effect of the insulation material thickness over different sample materials, the length of the bar was fixed in $Z_{M}=100 \mathrm{~mm}$ and the evaluation temperature was set in $T E=200{ }^{\circ} \mathrm{C}$. The thickness of the insulation material is defined as the difference between the insulation radius $\left(r_{A}\right)$ and the reference material radius $\left(r_{R}\right)$ or the sample material radius $\left(r_{M}\right)$. When the reference material is Stainless steel, the error decreases from 3.02 to $1.89 \%$ when the sample material is Asbestos $(\lambda=0.58$ $\left.\mathrm{W} \cdot \mathrm{m}^{-1} \cdot \mathrm{K}^{-1}\right)$ as the insulation material increases from 25 to $100 \mathrm{~mm}$. A similar behavior can be seen for the Bakelite $\left(\lambda=1.4 \mathrm{~W} \cdot \mathrm{m}^{-1} \cdot \mathrm{K}^{-1}\right)$ where the error varies from $1.15 \%$ to $0.62 \%$ as the insulation thickness varies too. For materials with thermal conductivity value of 


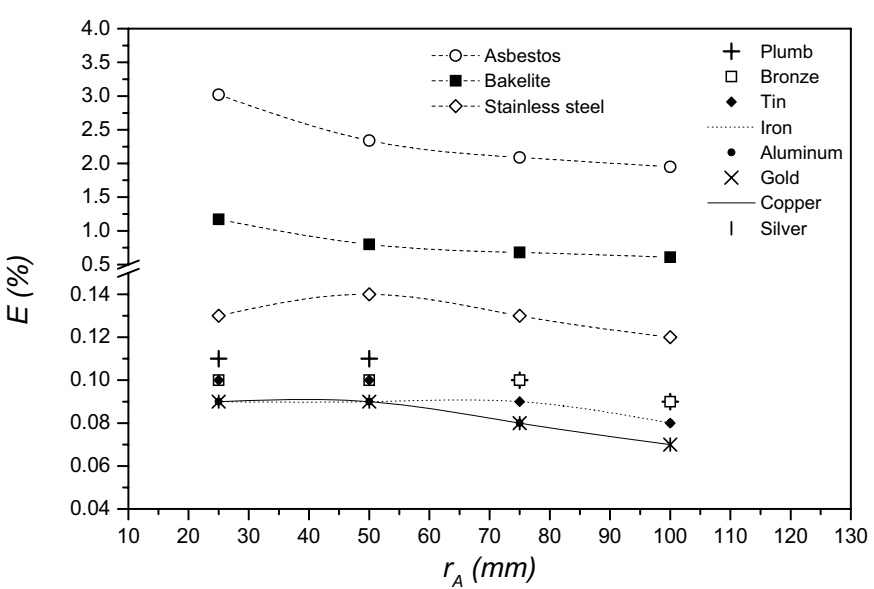

(a)

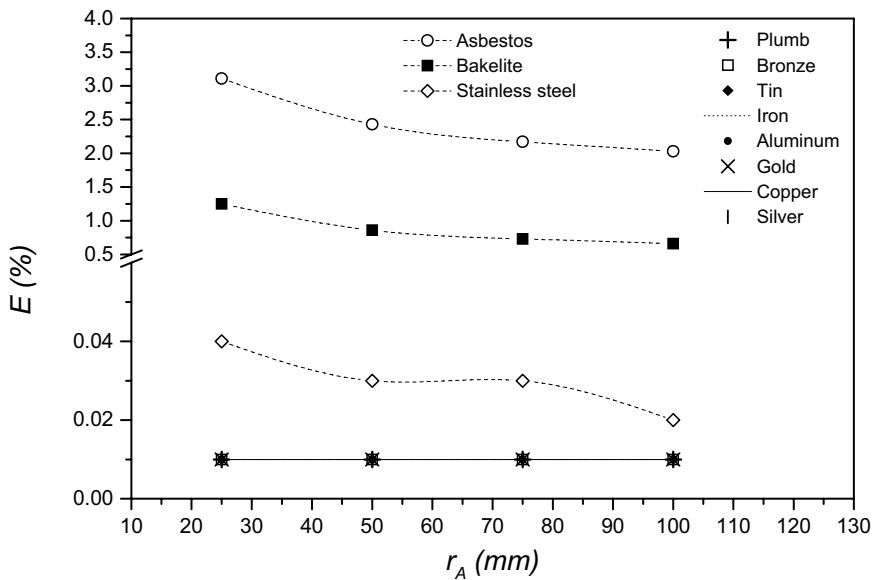

(b)

Fig. 10. Maximum error design as a function of the insulation material thickness for all the sample materials under study with: (a) Stainless steel and (b) Copper as the reference material.

$\lambda \geqslant 14.2 \mathrm{~W} \cdot \mathrm{m}^{-1} \cdot \mathrm{K}^{-1}$, the design error remains practically constant within the same interval of the insulation thickness with a value of $0.14 \%$. Similar results are obtained when the reference material is Copper; the highest error is get for the material with the lowest thermal conductivity value (Asbestos), which goes from 3.11 to $2.11 \%$ and corresponds to the insulation material radius from 25 a $100 \mathrm{~mm}$.

\subsection{Effect of the sample material length $\left(Z_{M}\right)$}

Even though the Standard ASTM E1225 [6] suggests that the radius between the thermal conductivity value and the sample material length (conductance) has to be the same for both the sample and the reference material, the length of the sample material is a parameter not defined yet in the design of systems for measuring thermal conductivity Because in this study 4 values for the length of the sample and 11 sample materials were defined, the combination of these two parameters gives 44 different cases. Therefore, we only show the most relevant case

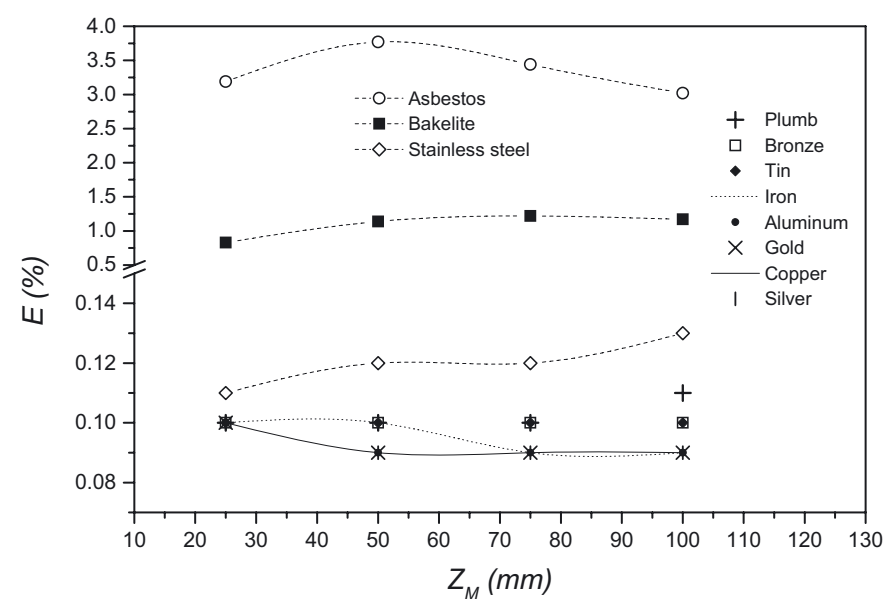

Fig. 11. Maximum error design as a function of the sample material length for all the sample materials under study with Stainless steel as the reference material.

representing the highest design error. For this section the insulation material $\left(r_{A}\right)$ was fixed in $25 \mathrm{~mm}$, the evaluation temperature at $T E=200{ }^{\circ} \mathrm{C}$ and the reference material was Stainless steel.

Figure 11 shows the maximum percentage design error as a function of the length of the sample materials. The results show that the percentage error corresponding to the Asbestos sample material $\left(\lambda=0.58 \mathrm{~W} \cdot \mathrm{m}^{-1} \cdot \mathrm{K}^{-1}\right)$ increases from 3.19 to $3.77 \%$ for the sample length going from 25 to $50 \mathrm{~mm}$; after that the error decreases to $3.02 \%$ when the sample length reaches $100 \mathrm{~mm}$. The error for the Bakelite sample material $\left(\lambda=1.4 \mathrm{~W} \cdot \mathrm{m}^{-1} \cdot \mathrm{K}^{-1}\right)$ shows an increment from 0.83 to $1.17 \%$ as the sample length varies from 25 to $100 \mathrm{~mm}$. For the Stainless steel sample material $\left(\lambda=14.2 \mathrm{~W} \cdot \mathrm{m}^{-1} . \mathrm{K}^{-1}\right)$ the increment in the design error is minimum, going from 0.11 to $0.13 \%$ when the sample length varies from 25 to $100 \mathrm{~mm}$. For practical purposes, the error for sample materials with high thermal conductivity value $\left(\lambda \geqslant 52 \mathrm{~W} \cdot \mathrm{m}^{-1} \cdot \mathrm{K}^{-1}\right)$ can be taken as constant with a value not higher than $0.10 \%$. Similar results were obtained for even higher thermal conductivity samples.

\subsection{Effect of the temperature evaluation (TE)}

Temperature evaluation (TE) is the arithmetic average between the high temperature (heat source) and the low temperature (heat sink) of the measurement system and it is considered as the temperature at which the thermal conductivity of the sample material is reported. The importance of this parameter is that all materials used on an everyday life work at different temperatures according to their application.

Figure 12 presents the maximum percentage design error as a function of the different evaluation temperatures for some sample materials. In order to analyze the effect of the evaluation temperature only over the different sample materials, the sample length was fixed at $Z_{M}=100 \mathrm{~mm}$, 


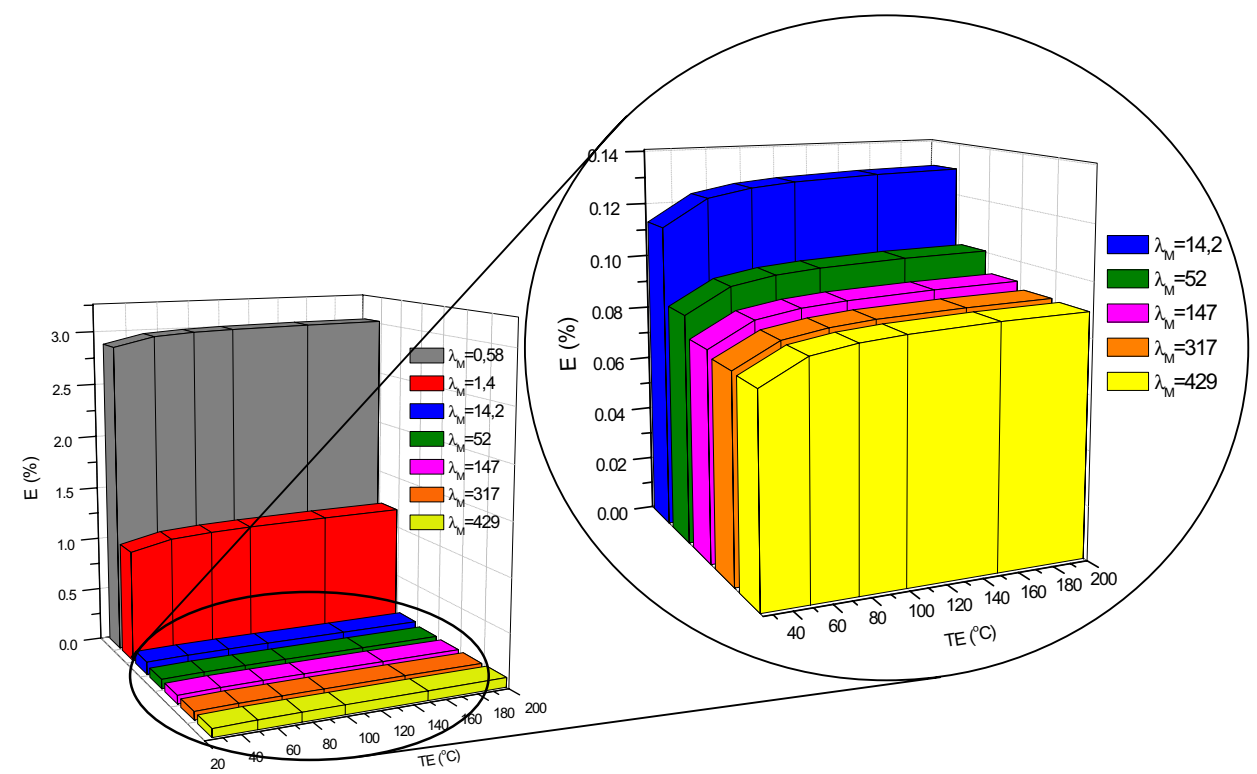

Fig. 12. Maximum error design as a function of the temperature evaluation for some sample materials under study with Stainless steel as the reference material.

the insulation material radius was set as $r_{A}=25 \mathrm{~mm}$ and Stainless Steel was defined as the reference material, all these parameters correspond to the cases with the highest error design. It is observed, that the percentage error for the Asbestos material varies from 2.77 to $3.1 \%$ as the evaluation temperature varies too from 25 to $200{ }^{\circ} \mathrm{C}$. Variation of the percentage error for the Bakelite $\left(\lambda=1.4 \mathrm{~W} \cdot \mathrm{m}^{-1} \cdot \mathrm{K}^{-1}\right)$ sample goes from 0.95 to $1.0 \%$ in the same evaluation temperature interval. For sample materials with thermal conductivity $\lambda \geqslant 14.2 \mathrm{~W} \cdot \mathrm{m}^{-1} \cdot \mathrm{K}^{-1}$, the contribution to the design error is low compared to the materials with very low thermal conductivity, and it lies between 0.05 and $0.13 \%$. In general, variation of the design error for materials with high thermal conductivity value is small, being relatively noticeable within the interval of 25 to $50{ }^{\circ} \mathrm{C}$, beyond this temperature the error remains constant as the evaluation temperature increases.

\subsection{Effect of the reference material $\left(\lambda_{R}\right)$}

The role of the reference material is very important to determine the thermal conductivity of the sample material. The main characteristic of the reference material is its thermal conductivity; therefore, four materials with different thermal properties were selected, in order to be able to identify the more appropriate one according to its application with a minimum design error.

In this section, in order to quantify the effect of the reference material the following parameters were set: radius of the insulation material $\left(r_{A}\right)$ in $25 \mathrm{~mm}$, evaluation temperature $(T E)$ at $200{ }^{\circ} \mathrm{C}$ and the sample length $\left(Z_{M}\right)$ in 25 and $100 \mathrm{~mm}$; these parameters correspond to the cases where the highest percentage error was obtained.

Figure 13 shows the maximum percentage error as a function of the reference material used in all the sample materials. The highest design error is obtained when using Stainless steel $\left(\lambda_{R}=14.2 \mathrm{~W} \cdot \mathrm{m}^{-1} \cdot \mathrm{K}^{-1}\right)$ as reference material $(3.19 \%)$. The error decreases when the thermal conductivity of the reference material increases, the error becomes constant from the Aluminum $\left(\lambda_{\mathbf{R}}=237.0 \mathrm{~W} \cdot \mathrm{m}^{-1} \cdot \mathrm{K}^{-1}\right)$. In particular, for the Asbestos $\left(0.58 \mathrm{~W} \cdot \mathrm{m}^{-1} \cdot \mathrm{K}^{-1}\right)$ case the sample material with length $Z_{M}=25 \mathrm{~mm}$ (Fig. 13a), the error design varies from 3.19 to $2.92 \%$ corresponding to Stainless Steel and Copper $\left(\lambda_{R}=401 \mathrm{~W} \cdot \mathrm{m}^{-1} \cdot \mathrm{K}^{-1}\right)$ as the reference materials respectively. For the Bakelite as the sample material, the error goes from 0.83 to $0.66 \%$ for the same reference materials used. For the remaining sample materials (Stainless steel, Plumb, etc.) the design error associated to the effect of the reference material can be taken as constant with a maximum value of $0.1 \%$. Similar results show when the length of the sample material is set as $Z_{M}=100 \mathrm{~mm}$ (Fig. 13b), the highest error is obtained for the lowest thermal conductivity sample material (Asbestos), going from 3.0 to $3.11 \%$

\section{Conclusions}

Based on the study of heat transfer focused on the thermal design of a cut bar instrument to determine the thermal conductivity of solid materials, the following conclusions are presented:

(a) Effect of the insulation material: it is recommended to use the maximum thickness for the insulation material $87.5 \mathrm{~mm}$ ( or $r_{A}=100 \mathrm{~mm}$ ) when the thermal conductivity of the sample material lies between 0.58 to $14.2 \mathrm{~W} . \mathrm{m}^{-1} . \mathrm{K}^{-1}$; using this thickness the maximum percentage design error is $2.11 \%$. When the thermal conductivity of the sample material goes 


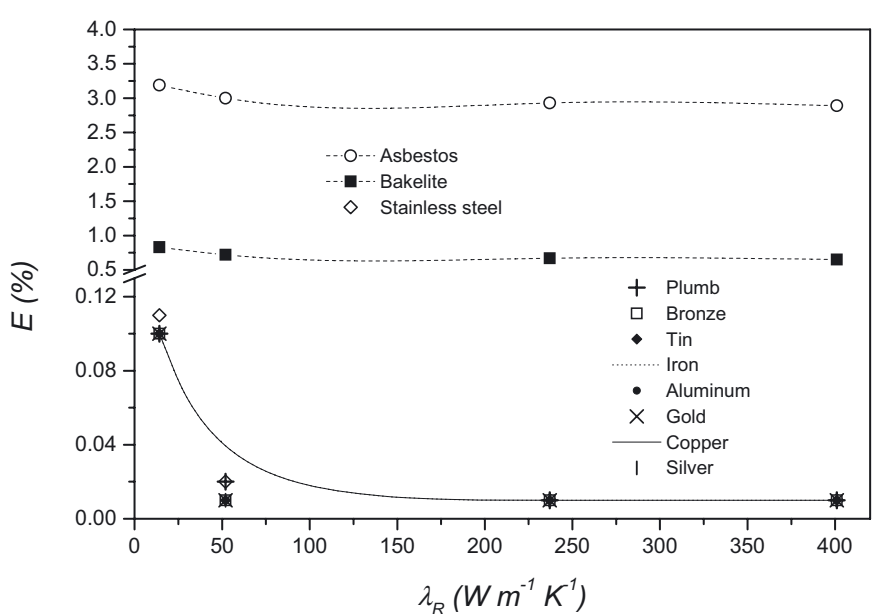

(a)

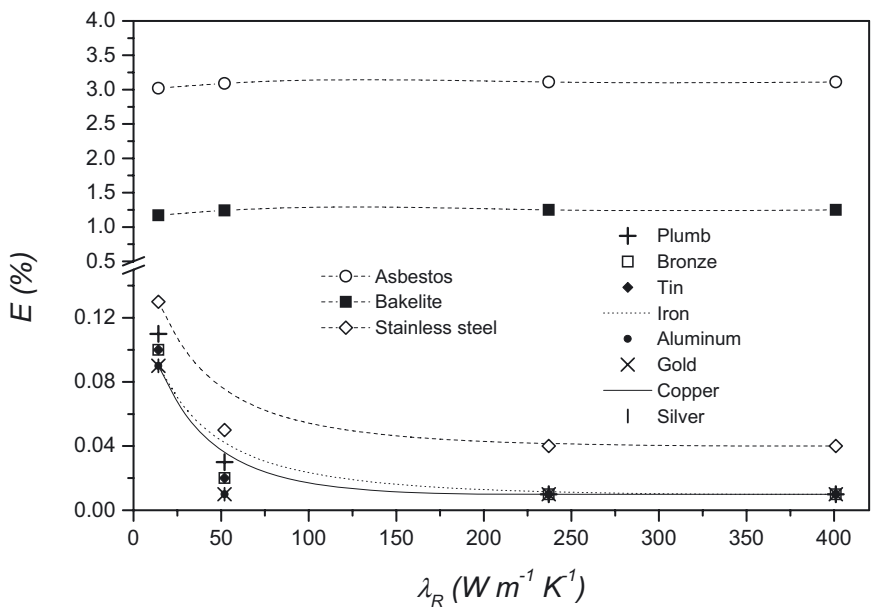

(b)

Fig. 13. Maximum design error depending on the reference material, for different sample materials: (a) $Z_{M}=25 \mathrm{~mm}$ and (b) $Z_{M}=100 \mathrm{~mm}$.

beyond this value $\lambda \geqslant 14.2 \mathrm{~W} \cdot \mathrm{m}^{-1} \cdot \mathrm{K}^{-1}$, it is recommended to set the thickness of the insulation material in $12.5 \mathrm{~mm}\left(r_{A}=25 \mathrm{~mm}\right)$, since the maximum error obtained is $\sim 0.14 \%$.

(b) Effect of the material length: it is recommended to set the sample length in $Z_{M}=100 \mathrm{~mm}$ when its thermal conductivity is between 0.58 and $52.0 \mathrm{~W} \cdot \mathrm{m}^{-1} . \mathrm{K}^{-1}$; in all these cases the maximum design error was obtained with the Asbestos (3.02\%). For sample materials with thermal conductivity higher than $52 \mathrm{~W} \cdot \mathrm{m}^{-1} \cdot \mathrm{K}^{-1}$ any length can be used $\left(25 \leqslant Z_{M} \leqslant\right.$ $100 \mathrm{~mm}$ ), in these cases, the error can be taken as constant with a value lower than $0.10 \%$.

(c) Effect of the evaluation temperature: based on the results it was observed that for the analyzed evaluation temperature $\left(25 \leqslant T E \leqslant 200{ }^{\circ} \mathrm{C}\right)$, the maximum design error obtained was $3.1 \%$, which corresponds to the Asbestos as the sample material, this value decreases to $1.0 \%$ for the Bakelite, and for materials with thermal conductivity $\lambda \geqslant 14.2 \mathrm{~W} \cdot \mathrm{m}^{-1} \cdot \mathrm{K}^{-1}$ the design error is $\leqslant 0.13 \%$. (d) Effect of the reference material: It is recommended to set overall the sample material length $\left(Z_{M}\right)$ in $100 \mathrm{~mm}$, with this length the maximum design error varies from 3.0 to $3.11 \%$ corresponding to Stainless steel and Copper respectively as the reference materials and Asbestos as the sample material. For sample materials with a thermal conductivity equal or higher than $1.4 \mathrm{~W} \cdot \mathrm{m}^{-1} \cdot \mathrm{K}^{-1}$, the error can be taken in general, as $1.0 \%$ for the reference materials considered in this study.

In general, the thermal design of a cut bar instrument to determine the thermal conductivity of solid materials within the interval $0.58 \leqslant \lambda \leqslant 429 \mathrm{~W} \cdot \mathrm{m}^{-1} \cdot \mathrm{K}^{-1}$ shows a maximum design error of $3.77 \%$ associated to the length of the sample material. The recommendations in the previous subsections allow one to know the error by design which can be taken into account as a source of uncertainty when determining the thermal conductivity of solid materials.

Acknowledgements. The authors are grateful to the Consejo Nacional de Ciencia y Tecnología (CONACYT), whose financial support made this work possible.

\section{References}

[1] F. Incropera, Fundamentals of heat and mass transfer, John Wiley \& Sons, 2002

[2] ASTM C 518, Standard test method for steady-state thermal transmission properties by means of the heat flow meter apparatus, 2002

[3] ASTM C 1113, Standard test method for thermal conductivity of refractories by hot wire (platinum resistance thermometer technique), 1999

[4] ASTM C 177, Standard test method for steady-state heat flux measurements and thermal transmission properties by means of the guarded-hot-plate apparatus, 2004.

[5] ASTM F 433, Standard practice for evaluating thermal conductivity of gasket materials, 2002

[6] ASTM E 1225, Standard test method for thermal conductivity of solids by means of the guarded-comparativelongitudinal heat flow technique, 2004

[7] ASTM E 1461, Standard test method for thermal diffusivity by the flash method, 2001

[8] R. Tye, The measurement of thermal conductivity by comparative method, in: Compendium of thermophysical property measurement methods, edited by K.D. Maglic, A. Cezairliyan, V.E. Peletsky, Plenum Press, 1992, 77-97

[9] R. Barea, R. Marin, M.I. Osendi, R. Martinez, P. Miranzo, Equipo comparativo para la medida de conductividad térmica de materiales cerámicos (Comparative device for measuring thermal conductivity of ceramic materials), Cerámica y vidrio 45 (2006) 80-86

[10] F. Jones, F. Pascal, Numerical simulation of divided-bar thermal conductivity measurements, Studia geophysica et geodaetica 37 (1993) 234-257 
[11] L. Lira, R. González, E. Méndez-Lango, Sistema de medición de la conductividad térmica de materiales sólidos conductores, diseño y construcción (Measuring system of thermal conductivity in solid conductive materials), Simposio de Metrología, CENAM, Santiago de Querétaro, Qro., 2008, 1-11

[12] A. Slifka, Thermal-conductivity apparatus for steadystate, comparative measurement of ceramic coatings, J. Res. Nat. Inst. Stand. Technol. 105 (2000) 591-605

[13] J. Albáñes, F. Abellán, R. Valerdi, J. García, Conductividad térmica de una barra de cobre. Estudio experimental del transitorio (Thermal conductivity of a copper bar. Experimental study of the transient), LatinAmerican J. Phys. Educ. 2 (2008) 259-267

[14] C. Xing, C. Jensen, H. Ban, J. Phillips, Uncertainty analysis on the design of thermal conductivity measurement by a guarded cut-bar technique, Meas. Sci. Technol. 22 (2011) 075702

[15] C. Xing, C. Jensen, H. Ban, J. Phillips, Error evaluation of a thermal conductivity measurement system for TRISO fuel compact, American Nuclear Society, Annual Meeting Hollywood, FL 2011, 293-294

[16] C. Jensen, C. Xing, H. Ban, J. Phillips, Validation of a thermal conductivity measurement system for fuel compacts, Proc. ASME/JSME 2011 8th Thermal Eng. Joint Conf., Honolulu, Hawaii, USA 2011, 1-10
[17] C. Jensen, C. Xing, C. Folsom, H. Ban, J. Phillips, Design and validation of a high-temperature comparative thermal-conductivity measurement system, Int. J. Thermophys. 33 (2012) 311-329

[18] S. Reif-Acherman, Early and current experimental methods for determining thermal conductivities of metals, Int. J. Heat Mass Transfer 77 (2014) 542-563

[19] Ch. Xing, C. Jensen, Ch. Folsom, H. Ban, Douglas W. Marshall, An optimal guarding scheme for thermal conductivity measurement using a guarded cut-bar technique, part 1 experimental study, Appl. Thermal Eng. 62 (2014) 850-857

[20] Changhu Xing, C. Jensen, Ch. Folsom, H. Ban, D. W. Marshall, An optimal guarding scheme for thermal conductivity measurement using a guarded cut-bar technique, part 2 guarding mechanism, Appl. Thermal Eng. 59 (2013) 504-514

[21] S. Patankar, Numerical heat transfer and fluid flow, Hemisphere Publishing Co., New York, 1980

[22] J. Esquivel-Ramón, Diseño térmico de un instrumento de barras cortadas para medir conductividad térmica de sólidos conductores (Thermal design of cut bar instrument to measure thermal conductivity of solids conductors materials), Master Thesis, CENIDET, 2010

[23] M.N. Özisik, Heat Conduction, McGraw-Hill, 1993 